\section{THE METHODOLOGY OF PROJECT MANAGEMENT OF SOFTWARE DEVELOPMENT AT THE NATIONAL BANK OF SERBIA}

\author{
Goran Kunjadić1, Milan M. Milosavljević ${ }^{2}$ \\ ${ }^{1}$ National Bank of Serbia, Belgrade, Serbia \\ ${ }^{2}$ Faculty of Informatics and Computing, Singidunum University, Belgrade, Serbia
}

\begin{abstract}
:
Project management methodology is of great importance because it defines a way of keeping the project to its successful completion. There are many methods developed based on different theoretical assumptions. Each of the methods has been developed on the basis of the specific needs of the system in which it is used and it cannot be unambiguously mapped to another system. The proposed methodology is developed based on the specific needs of project management of software development at the National Bank of Serbia. The proposed solution in large measure can be used in other central banks as well as commercial banks.
\end{abstract}

\section{Key words:}

Project Management, National Bank of Serbia, Application Software Development.

\section{INTRODUCTION}

Project management methodology defines all the activities that need to be implemented to manage the project from the start to the finish. It describes in detail each step in the life cycle of the project.

The methodology of project management of software development at National Bank of Serbia was defined according to the specific needs of the Bank, according to the type and size of projects that are being developed as well as to the number of projects simultaneously.

The project was time limited, one-time activity, which is clearly defined:

- specific goals,

- start date,

- end date,

- conditions under which it is implemented,

- assigned responsibilities,

- budget

- schedule

which involves more interested businesses.

- Initialization

- Planning

- Development (execution and control)

- Closing

The methodology of project management of software development provides the framework for all tasks, proce- dures and reports required to be implemented throughout the project, and ensures that development projects be consistent and aligned with the best international practices [1].

\section{INITIALIZATION}

Each project begins with an idea to develop a product, service, or implementing a desired activity.

At this stage, to determine the nature and scope of the project, define the basic information about the project, to design and objectives to be achieved. This is the phase in which performs a rough estimate of the time required for the project.

In this phase, implemented the following activities:

\section{The proposal for the project}

The proposal for the project, usually comes from the business functions of the Bank.

As part of these activities are defined:

- Reasons for the project;

- Project objectives to be achieved;

- Vision development project.

The proposal for the project may come from IT when it comes to significant changes in technology, or when it is determined to be able to implement a new technology or business functionality (business intelligence, data warehouse...) 


\section{Description of business functionality}

Description of the business functionality of the activity in which you describe in detail the business processes. Most often it is a business process that:

- Provide the necessary processing information;

- Ensure that the required services are effective or introduce new services;

- Reduce costs.

Do a detailed description of the business functionality is mostly there through a series of meetings. Another way is to user selectable detailed business requirement in which the smallest detail to the description of business functions [2].

\section{FEASIBILITY STUDY (FOR STRATEGIC PROJECTS)}

For strategic projects is always recommended doing a feasibility study, to clearly recognize that it is more profitable for the Bank to the project of software development work or to buy the finished product. These studies always start from the current situation, define the desired state, and all the necessary steps from the current to the desired state.

\section{Scope of the project}

The scope of the project which defines all the business activities to be implemented during the project. The scope of the project defines what activities are part of the project and what parts are not the part of the project.

\section{Job description of each team member}

Already in the initialization phase is required, roughly, to determine what types of jobs will run the project team members. For larger projects (over 10 team members), the practice is to create a table containing detailed job descriptions for all team members, the manner in which these activities are adjusted and how and who co-ordinates. Job descriptions for all team members are also part of the project plan.

\section{Report on project status}

It is common to management reporting on project status weekly. For leadership is important to keep up to date with the activities that were implemented and the overall progress of the project.

Reporting on the status of the project is an integral part of the communication process.

\section{Report on the activities realized within the initialization phase}

At the end of the initialization phase, the project manager can write a report on all the activities that have been implemented at this stage. This report is mainly created if at this stage there were no major problems, in which case describes how the problems are solved and makes a list of all the (previously identified) critical points [3].

\section{PLANNING}

The planning phase is the most important phase in the process of project management [4].

The objective of this phase is to:

- More clearly define the scope of the project

- Establish a precise plan costs

- Defines the planned outputs of the project and their dates

- Establish the organization of the project

- Provide the necessary approvals management

- Provide a framework for project management review and control.

Basic processes, which at this stage must be carried out are:

- Estimate the size of the project

- Evaluation of the technical scope of the project (the necessary hardware, software and services)

- Estimate the resources needed

- Creating a plan

- Identification and assessment of risks

\section{Project plan}

Project plan is a mandatory document in the planning phase of the project, in fact, describes the strategy of development of the project.

Project plan must be formally approved and on the guide and in the implementation phase, a significant element of control of the project.

\section{Resource plan}

Plan resources used to identify all the resources that are needed to make the project finished. When identifying needs, then it is possible to define a resource plan.

\section{The Financial plan}

For strategic projects, for which there is no predefined budget, makes the financial plan. The financial plan enables you to compare the budget with costs. To implement this project "within budget" it is necessary that all output files are created so that the total cost does not exceed the allocated budget.

The financial plan for the project is created in such a way as to define in detail all the items on both the revenue and expenditure side.

The financial plan helps you define:

Monitoring the implementation of the project budget is extremely important. The financial plan helps you realize the objectives of the project within the designated 
funds. For the project manager is to create a financial plan is one of the most critical tasks.

\section{Quality control plan}

Plan project quality means to define the level of quality project that will provide such output statements, or products that will the best ensure that the project is implemented in accordance with the requirements of the user.

In order to achieve the desired quality of the project, it is necessary to pre-determine the activity of the quality control of the project.

Quality Planning is an important part of every project. Plan quality enables to set up a set of control points in order to control and to define requirements for quality control.

In this way, the user is verified, with a high degree of certainty that the project will be successfully implemented.

The plan defines the quality control at the beginning of the project manager and project controller quality.

\section{Risk management plan}

Risk management plan helps identify risks and minimize the impact of identified risks.

This plan defines all the activities that need to be taken to avoid or minimize the risk. In this way it is possible to effectively control and monitor risks, thereby increasing the likelihood that the project is completed successfully.

Risk management plan helps to:

- Identify the risks

- Set priorities and the level of risk

- Determine the probability of occurrence of risk

- Determine the impact that will have on the project risk

Risk Management Plan to use:

- identify preventive measures to forestall the risk

- prepare a list of actions to be taken if the risk is, however, demonstrate

- plan activities in real-time

- We monitor the status of each risk, for the entire duration of the project.

Creating a risk management plan is one of the critical steps in the development of the project. Creating this plan helps reduce the probability of the risk occurrence happens.

Risk Management Plan helps anticipate risks, to identify actions to prevent and reduce the impact on the project if the risk event, however, happen. Under this plan, it is necessary to list all the risks that it is possible to predict, their priorities, preventive actions and activities to minimize the impact of risk occurrence, and the ways in which risk will be monitored phenomena.

The risk management plan is used each time the project manager estimates that there are risks that may affect the success of the project. For example, at the beginning of the project, it is necessary to record all the risks that may occur during the project. It should be permanent, according to plan, control all risk in order to ensure that risk is avoided, or minimized, the fastest, possible, way. Risk management plan is an integral part of the project plan.

\section{Plan acceptance of the project}

This program helps users to be sure that they accept all output products.

Creating a Plan for acceptance (or acceptance test plan for the project) is an important part of every project. This plan defines the conditions under which the user will find that the project is successfully implemented in accordance with business process.

Acceptance of the plan should include:

- A list of all parameters that are important for the acceptance of the project

- A list of all criteria

- Establishment of standards that need to be respected

Acceptance of the plan is designed so as to:

- Identify and adopt testing methods

- Determine the users who will participate in the process of accepting

- Defines a schedule for admission (for complex projects)

Acceptance of the plan is a schedule of activities to be implemented in consultation with users, to be clearly defined acceptance criteria, and that the project was in line with expectations. This plan defines precisely, for all participants involved in the project, how should it look like the output products that result from the project.

Plan acceptance is generally created for complex projects. When the user is expected to formally approve the results of the project, especially if the project was implemented in several phases (and each is a prerequisite for the next stage), then the plan is essential. Even for simpler projects, this document clearly defines what the user will get. The decision about whether to be created this document provides the project manager.

\section{Communications plan}

Communications Plan (or plans communication) define the best way that you can convey the right message to the right people at the right time. As part of the communication plan describes the objectives of the plan are determined by the participants in the communication process, communication strategies, activities and time frame in which the process of communication, which is defined by the plan, to be implemented. Defining the communication plan is the best way to achieve that all participants be well-informed and to send a consistent message to all interested parties.

Planning means of communication is an important part of any business process. Communications Plan ensures that all participants in business process are properly and timely informed. 
The plan defines the communication time plans for all significant events (introductory meeting, presentations and other meetings, the final meeting, etc.)

Communication plan should include:

- A list of all participants of the project and a list of information they need

- Identified all the important events, for the duration of the project

- Defining events frequency (for example, meeting the team members once a week, management reporting every first of the month, etc.)

- Allocation of necessary resources

- Timelines maintenance of significant events

By means of the communication plan is also possible:

- Keep track of all the important events

- Get feedback

- Improve the communication process

Communications Plan is necessarily true when a large number of members of the project team when the team members from different organizational units, where there are participants in team who are not employed in work organization, then it is simply necessary to have formally defined communication plan. Clearly defined communication plan is essential for good project organization. At the same time, it is also a critical point of the project because it is the only way to ensure that everyone, and users, and indirectly, members of the development team, on time and fully informed about the progress of the project. The best moment for defining a draft communication plan is during the very beginning of the project. Communication plan is an integral part of the project plan.

\section{Report on the activities implemented within the planning phase}

These statements are made in writing to the strategic, long-term and complex projects.

Report on the activities that are carried out in the planning phase is complete at the end of the planning phase. When this report is approved by the competent manager may be looking at the next phase (phase of implementation). This report describes the risks and problems that have emerged in this stage, and the manner of their resolution (reductionism, to overcome). [5] In this report shows:

- Whether the project is implemented on schedule and within budget

- Are there any output document (project) and are approved

- Whether the risk is analyzed and whether it is under control

- Are the problems solved

The report helps to:

- document the results of the project phases

- Clearly see the progress of the project (and to show the sponsor)

- List all the risks and impacts

- It is noted that all activities carried out on time
- Obtained approval for continuation of the project (next phase).

For projects that do not fall within the strategic, longterm or complex, the activities carried out in this project phase can be described by a competent manager of the orally.

\section{REALISATION}

\section{Time management}

The best way to see if it is implemented as expected to follow the ratio of the planned and actual time spent for the implementation of planned activities. The process of time management allows us to, for each task (job), we see that there is (was) completed on time. To make the process of time management implemented, it is necessary to record all the time that participants spent on the project for the implementation of tasks.

The process of time management helps identify and resolve problems that arose because of inadequate schedule, and all the time we have an updated schedule.

In order for this to be realized it is necessary:

- Record all necessary steps to manage the time during the project

- Describe the roles and responsibilities of all members of the project team and the time needed for implementation

Form for recording time is required to accurately record the time they spent engaged in the project in executing tasks (jobs). You need to fill in this form in all cases where we want to have an accurate record of the time that is needed to realize the project.

Filling in the form helps to:

- Supervise and control the time employees working on tasks that are defined in the project plan

- Record all activities done

- Timely identify and solve all the problems related to time schedule

- Clearly see if the project is implemented on time

- Assists in planning time for implementation of certain phases of future projects

Time plan is an integral part of the project plan, and within the time schedule keep the records and time spent.

\section{Cost management and cost accounting}

Cost management is described in the document "Guidelines for the management of costs."

Under the instruction is defined and tables for monitoring costs.

Monitoring of project costs helps, for projects that have a fixed budget, stay within budget and to all the other projects that we know the material value of the realized projects.

Cost monitoring enables:

- Creating a report on all costs

- Identification of costs by different criteria (in phases, tasks, team members, types of costs) 


\section{Quality management and quality reporting}

Quality management project is a set of procedures to ensure that the output of the project completely filled in (predefined) user requirements.

The process of quality management of project include:

- Define a set of objectives that the project team is expected to reach in order to increase the quality of

- Define a set of measurable goals

- Activities on the measurement of quality

- Identification of possible improvements

- Complete coverage of the quality level of the whole project

Report on the quality of the work so that it can show that you have achieved the goals that you have good control standards in place, to rank the quality of output, to identify deviations from the quality and enumerate the necessary improvements. This report may also show whether all procedures in the field of quality monitoring respected and to facilitate the monitoring and control of all products and services.

Report on quality is created if one wants to get a clear picture of the quality of the project and the quality of work of the project team.

\section{Output documents}

Output document, which arise as a result of the project, the documents that are in the planning phase of the project is defined as a mandatory document that team members must complete. These documents are for the duration of the project (project life cycle) is always available to the sponsor of the project. Output document affecting the process of improving project management, process improvement of existing or introduction of new documents could affect the greater flexibility of resources, the establishment of best practices in project development, word fill these documents enable complete control over the project.

The practice is that the registry document output form only for extremely complicated and complex projects. A registry of document output, it is possible to monitor the progress of the project and monitor the quality of the project. Recording the current status of the output document, project team members can monitor and control the level of quality achieved

In this registry writes:

- Current status of output documents

- Target quality documents

- Quality criteria that we want to satisfy

\section{The process of change management}

Changes may occur at each stage of the life cycle of the project. The changes are due to changes in business processes, changes in work organization or organizational structure, due to the changed legislation and for a number of objective and subjective reasons.
The process of change management consists of a set of procedures that assist the project team to effectively control change. It is well known that we cannot, in the course of the project, to prevent the existence of changes in the project. The process of change management is defined as follow changes to control the effects of these changes, both on the development of the project and the business process.

When you define a change management process, in fact:

- Identifies the request for change

- Confirms that change is possible to perform

- Controls the way of implementing changes

- Control method for approving changes to the project

Part of the process of change management is:

- Providing the necessary forms for tracking changes

- a detailed description of each step in the change process

- Flowchart change (can be turned on to more complicated changes)

- Defining the responsibility for the implementation of changes

- Description of changes and approval process (change)

An effective process change management is a key function of any project team. Speed accepting the change affects the team's ability to respond to requests, which directly affects the cost of the project and during the project.

Create a form request for amendment, allows the project team to document all the changes and the manner of their implementation. The basic elements of the request for change is recorded in the registry changes.

Using the form of requests for changes are:

- Formal written all requests for change

- Identify all business requirements have caused (request for) change

- Analyze all costs and benefits in the event that the request is granted

- Describe the impact of changes

- rank the urgency (acceptance of change)

- Implemented a process of formal approval of changes

- Monitor the effects of implemented changes

Of change in the stored information about the changes:

- Nature of change (intrinsic or visual)

- The impact of changes on project and business process

- Who approved the change (and when)

- Timetable of implementation changes

- Current status of all changes

\section{The process of risk management}

This process describes all the necessary steps to be taken to identify, control and monitor risks. In this process it is possible to define risk as any event in the future that 
may prevent the project team to achieve the set goals. This process enables the identification of risks, quantifying the impact of the risk, and taking steps to avoid risk or reduce its impact.

When defining the process and the implementation of risk management in a project, you can monitor and control risks and avoid all the unknowns.

Work is project manager to decide whether this process will be implemented during the project development.

The required forms for the process of risk management is a form of risk assessment and risk register.

Form of risk assessment helps manage risk and to risk analysis division, with all team members. As part of the form describes activities that must be taken to avoid or minimize the risk. This enables risk mitigation in the fastest way possible. The form includes:

- Who is the identified risk

- The nature of the risk and who may be affected

- Probability of occurrence

- Impact on project

But it can also be used to:

- Defines the list of preventive activities

- Identify activities that can reduce the impact of risk

- Create and approve the review of activities in order to reduce

- Monitor and control the risk,

- Risk register is used in the monitoring of all risks (business process or project). This Registry records:

- Type of risk (reputational, financial, operational), who identified him and how it affects business process

- Probability of occurrence and potential impact

- Priority, based on the impact on business processes

- Activities to be undertaken preventive

When you define and use a risk register, it is possible to effectively monitor and control risks, identify actions that have been taken to avoid or reduce risks and report, at any time, on the status of risk.

\section{The process of managing the problem}

Management problem is a set of procedures that help solving the problem as soon as it is detected. It is common to, for the duration of the project, problems occur. Therefore, it is customary to record problems and to identify the actions that have been taken solve the problem. As part of the management of the problem is required to predict and approval of planned actions.

In the process of managing the problem of defining the two documents: Form for recording problems and registry problems.

If project establish such a register, then it is possible, at any time, inform the management about all the problems and possible impact that occurred during the life of the project.

\section{The process of communication}

One of the most important processes in the project. In the planning phase of the project is described in the planning process of communication. The process of communication should be a continuation of the planning process communication. This process helps us to timely notify all interested parties on all essential aspects of the project.

This process is defined when we want communications between participants in the project, for the duration of a project, to be formalized. A way of formalizing the communication does not eliminate informal means of communication of the team members.

\section{Testing, the process of acceptance and form of acceptance of the project}

Acceptance of the project is defined by a series of steps that need to be implemented to make users fill out and sign the form of acceptance of the project. Before that testing, is conducted how users fill in a form on the user performance test. Project Manager determines when and under what conditions will be carried out testing. Test plan is a mandatory document that is created at the end of the implementation phase.

After filling out the form on testing, users should review (again) all output files from the project and to agree that this is what their business application.

\section{Project status report}

Report on the status of the project is essential that all team members and customers were informed of what the status of the project.

This report is very important for the leadership. It is clear that if the project is progressing according to predefined and approved, the plan. Creating such a report is another element of insurance success of the project.

As part of the report on the status of the project can be defined as the activities carried out in the implementation phase of the project. If the project is implemented as planned, then this report has all the elements of a report that was created in the planning phase.

\section{CLOSING}

Phase closure is the fourth and last phase of the project life cycle. At this stage of the project formally ends and directs the complete report to the sponsor of the project.

This phase includes:

creation of documents that customers need to do their job (user manuals, etc.).

the creation of all other documents that are required for commissioning of production-made application solutions as well as

notification of all team members on the project's completion [6]. 


\section{Reports on the closure of the project}

Although it seems that this is the easiest part of the project, it is necessary to carry out activities that the project was formally completed. The first step is to determine that all the criteria set for the closure of the project are met and that all required documents are delivered to customers. In the end, it takes all team members and all members informed of the completion of the project.

When the project is complete, in the end, post implementation report that describes the degree of success of the project implementation and all relevant experience.

\section{Post implementation report}

To be able to assess the success of the project, it is, in the end, post implementation report, the necessity of this report the decision (with the approval of the immediate supervisor) brings Project Manager. This report is listed.

This report analyzes and how they successfully implemented process management: managing change and managing quality control.

\section{CONCLUSION}

Presented methodology is actively used in the National Bank of Serbia. The methodology provides results that the design of application software in the National Bank of Serbia. The methodology is based on the best international experience and can be applied in other organizations, with certain modifications and adjustments.

\section{LITERATURE}

[1] European Central Bank, "The European Central Bank, the Eurosystem, the European System of Central Banks“, Frrankfurt, Germanu, 2014.

[2] Bagarić Ivan, "Menadžment informacionih tehnologija", Univerzitet Singidunum, Beograd, 2010

[3] Project Management Institute, Practice standard for work breakdown structures, ISBN 10: 1-933890-13-4ISBN 13: 978-1-933890-13-5, Pennsylvania, USA, 2013.

[4] Baum Stephane, "Banque de France Digital initiative", Banque de France, Paris, France, 2014.

[5] Sorel Stephane, "SOFACT - Brief overview of BDF Software Factory,” Banque de France, Paris, France, 2014.

[6] Kunjadić Goran, "IPA Project in NBS IT Department Moving to a new NOC organisation", National Bank of Serbia, Paris, France, 2014. 